\title{
Primary Muscle Disease: Definition of a 25-kDa Polypeptide Myopathic Specific Chagas Antigen
}

\author{
C. A. Santos-Buch, ${ }^{1}$ A. M. Acosta, H. J. Zweerink, M. Sadigursky, \\ O. F. Andersen, B. F. von Kreuter, C. I. Brodskyn, C. SAdigursky, \\ AND R. J. CODY
Departments of Pathology and Medicine, Cornell University Medical College, New York, New York 10021; The Gonzalo Môniz Research Center, Salvador, Brazil; and the Department of Immunology and Inflammation Research, Merck, Sharp and Dohme Research Laboratories, Rahway. New Jersey

\begin{abstract}
The sera from patients with primary heart and skeletal muscle diseases, hospitalized patients without intrinsic muscle disease from an area endemic for Trypanosoma cruzi infections, and normal subjects $(N=693)$ were studied for the presence of immunoglobulin $\mathrm{G}$ (IgG) antisarcolemma activity using serologic methods. The prevalence of elevated serum IgG antisarcolemma activity from patients with chronic Chagas' cardiomyopathy, idiopathic cardiomyopathy, polymyositis, and Duchenne muscular dystrophy was $58.9 \pm 10.4 \%(N=101)(P<0.001$ when compared to normal subjects $)$. Two of twelve $(16.7 \%)$ patients with acute $T$. cruzi infection and parasitemia developed elevated antisarcolemma titers, and $9 / 46(19.6 \%)$ patients with chronic $T$. cruzi infection without evidence of cardiomyopathy yielded high antisarcolemma titers. On the other hand, patients with chronic $T$. cruzi infection with advanced cardiomyopathy yielded high antisarcolemma titers in $35 / 74(47.3 \%)(P<0.001$ when compared to normal subjects). Radioimmunoprecipitation showed a circulating antibody to a $25-\mathrm{kDa} T$. cruzi polypeptide (P25) in 16/17 (94.1\%) patients with advanced cardiomyopathy and $T$. cruzi infection. No such antibody was shown in 12 asymptomatic subjects with chronic $T$. cruzi infection. 1985 Academic Press. Inc.
\end{abstract}

\section{INTRODUCTION}

Primary skeletal and heart muscle diseases are a heterogeneous group with a diverse etiology. A common histopathologic feature is muscle lysis with focal chronic inflammation and fibrous tissue replacement. Some of these characteristics are sometimes associated in primary skeletal muscle diseases and thus, heart muscle loss with fibrous replacement is seen with Duchenne muscular dystrophy (1-3) and polymyositis $(4,5)$. After a variable length of time, primary heart muscle fiber destruction sometimes follows Coxsackie B virus myocarditis (6-8) and chronic Trypanosoma cruzi infection (9-12). In the absence of detectable virus, parasitosis or the characteristic chagasic apical ventricular aneurysm, the heart lesion is indistinguishable from non-ischemic congestive cardiomyopathy $(11,13,14)$.

The immune response also bears close similarities among primary skeletal and heart muscle diseases. Abnormal cell-mediated and humoral immune activity

\footnotetext{
${ }^{1}$ To whom reprint requests should be addressed: Department of Pathology, Cornell University Medical College, New York, N.Y. 10021.
} 
against muscle antigens have been measured in both groups of diseases (15-31). It is not known whether the abnormal immunity is a spurious phenomenon or whether it is related to the induction or evolution of the muscle fiber lesion (17, 24).

This report describes a study of patients with primary skeletal and heart muscle diseases to establish the possible participation of antibodies against sarcolemma antigens in the induction of the muscle fiber lesions. In the course of the investigation we discovered a $25-\mathrm{kDa}$ polypeptide antigen in $T$. cruzi which is defined by the sera of patients with advanced congestive cardiomyopathy (chronic Chagas' disease and idiopathic cardiomyopathy) and by several sera of patients with advanced skeletal muscle disease (polymyositis, Duchenne muscular dystrophy).

\section{METHODS}

\section{Serology}

Enzyme-linked immunoassay (ELISA). The ELISA procedure to measure IgG titers was modified from that described by Grant (32). Alkaline phosphataselabeled goat IgG-anti-human IgG (Miles Laboratories, Inc., Elkhart, Ind.) diluted in phosphate-buffered saline (pH 7.4) with $5 \%$ bovine serum albumin and $0.05 \%$ TWEEN 20, was used as the conjugated enzyme marker. The conjugated enzyme was titrated in an ELISA procedure for optimal dilutions before use. Ten micrograms of test antigen (see below) were applied to each well of a polystyrene microtiter plate (Ace Scientific Supply Co., Linden, N.J.). Twofold dilutions of sera, beginning at 1:20, were made and known positive and negative standard sera were included on each microtiter plate. Titers were read without knowledge of the source of the sera by comparison with the known titer $(1: 1280)$ of the positive standard antiserum. Titrations were done in duplicate and were reproducible within one twofold dilution.

Inhibition of ELISA. For inhibition studies to establish cross-reactivity, the test antigen $(1 \mu \mathrm{g}$ per well) was attached to the microtiter plate wells with polylysine (33). This was followed by a wash with phosphate-buffered saline with $5 \%$ fetal calf serum to prevent nonspecific binding. To effect inhibition, the second test antigen [venereal disease research laboratory antigen (VDRL), sarcolemmal membrane antigen preparation (SLA)] was diluted serially beginning at $10 \mu \mathrm{g}$ in the first well. The positive serum, concentrated at two dilutions from the endpoint, was then added. The remainder of the test was similar to ELISA (see above).

Anti-Coxsackie B (types 1 to 6 ) titers. These were determined in a blind study with preselected sera by the New York Hospital Microbiology Laboratory using Coxsackie $B$ types 1 to 6 antigens and a complement fixation microtiter procedure (34).

\section{Antigens}

Preparation of cardiac sarcolemma. Cardiac sarcolemma antigen was prepared by the method of Jones, et al. (35). Heterogeneic sarcolemma antigen was pre- 
pared from a ventricular homogenate of hearts of freshly killed rabbits (Pel-Freez Biologicals, Inc., Rogers, Ark.) trimmed of fat and connective tissue. A pathologist-examined normal heart ( $4 \mathrm{hr}$ postmortem) from a 52-year-old patient who had died because of a ruptured peptic ulcer was similarly processed to obtain human allogeneic SLA after removal of valves, coronary vessels, fat, and visible connective tissue. The cardiac sarcolemma vesicles were resuspended in $0.25 \mathrm{M}$ sucrose, $10 \mathrm{~m} M$ histidine to a final protein concentration of $6-10 \mathrm{mg} / \mathrm{ml}$ and stored at $-70^{\circ} \mathrm{C}$ before use.

Preparation of actomyosin-extracted microsomes from human heart. Microsomes were prepared according to the procedure of MacLennan (36). All steps were carricd out at temperatures between 0 and $10^{\circ} \mathrm{C}$. The washed myocardium of a normal human male heart ( $3 \mathrm{hr}$ postmortem) was dissected free of epicardial fat, arteries, veins, and valve tissue before the extraction protocol. For storage at $-70^{\circ} \mathrm{C}$, the suspension of actomyosin-extracted microsomes was diluted to 10 $\mathrm{mg} / \mathrm{ml}$ by the addition of $1.5 \mathrm{vol}$ of $0.66 M$ sucrose, $0.05 M$ Tris (hydroxymethyl)aminomethane- $\mathrm{HCl}, 0.001 M$ histidine, $\mathrm{pH} 8.0$.

Growth and labeling of T. cruzi. The T. cruzi MERC 2 D14 clone was used in these studies (37). Epimastigotes were labeled with $\left.{ }^{35} \mathrm{~S}\right]$ methionine according to published technique (38). Between 60 and $80 \%$ of the ${ }^{35}$ S]methionine was incorporated into acid precipitable material. Parasites were harvested and stored as pellets containing $2 \times 10^{7}$ epimastigotes at $-70^{\circ} \mathrm{C}$.

Radiolabeled amastigotes were obtained from irradiated $T$. cruzi infected myoblast cells grown in $75-\mathrm{cm}^{2}$ culture flasks (37). At 3 days after infection when intracellular amastigotes began to appear, the cultures were labeled with $\left[{ }^{35} \mathrm{~S}\right]$ methionine, as described above, in $5 \mathrm{ml}$ medium per flask. After the label and chase period, cultures were washed twice with $0.04 M$ sodium phosphate, $0.15 \mathrm{M} \mathrm{NaCl}, \mathrm{pH} 7.4$ (PBS), and cells were removed from the surface by vigorous shaking in $10 \mathrm{ml}$ PBS containing $0.02 \%$ disodium ethylene diamine-tetraacetate (EDTA), $0.05 \% \mathrm{NaHCO}_{3}$, and $10^{-1} \mathrm{mM}$ each of $\mathrm{N}$-2-tosyl-L-lysine chloromethyl ketone (TLCK) and phenylmethylsulfonyl fluoride (PMSF). Cells were centrifuged at $400 \mathrm{~g}$ for $5 \mathrm{~min}$, washed once in PBS plus PMSF and TLCK, and stored at $-70^{\circ} \mathrm{C}$ as pellets containing $200 \mu \mathrm{g}$ protein each.

Radioimmunoprecipitations. Pelleted parasites $\left(2 \times 10^{7}\right)$ or infected myoblast cells $(200 \mu \mathrm{g})$ were lysed by sonication in $0.5 \%$ sodium dodecyl sulfate (SDS) as previously described (38). Immune complexes were recovered with Staphylococcus protein A immunoabsorbent following the precautions outlined in published techniques (38). Resolution of the $T$. cruzi antigens defined by immune complexes was done by discontinuous polyacrylamide slab gel electrophoresis in SDS as previously described. The fixed gels were impregnated with $\mathrm{EN}^{3} \mathrm{HANCE}$ (New England Nuclear, Boston, Mass.) as suggested by the manufacturer and dried and exposed to X-Omat AR film (38) (Eastman Kodak Co., Rochester, N.Y.). Molecular weight markers were ${ }^{14} \mathrm{C}$-labeled phosphorylase $(94,000 \mathrm{Da})$, albumin $(67,000 \mathrm{Da})$, ovalbumin $(43,000 \mathrm{Da})$, carbonic anhydrase $(30,000 \mathrm{Da})$, and trypsin inhibitor $(20,100 \mathrm{Da})$. These were radiolabeled with $\left[{ }^{14} \mathrm{C}\right]$ acetic anhydride as described (38). 


\section{Patient Populations}

All subjects, except 18 with secondary syphilis, were VDRL negative ( $N=$ 693). With the exception of 132 patients with Chagas' disease and 9 patients from non-endemic areas with secondary syphilis, all subjects had negative $T$. cruzi serology. Positive serology for $T$. cruzi infection was established by ELISA, complement fixation, and hemagglutination tests $(39,40)$.

Normals. Seventy asymptomatic healthy volunteers, 18 to 80 years old (mean $35), 24$ females and 46 males, from a non-endemic area for $T$. cruzi infection were used as controls.

Hospitalized subjects without primary myocardial or skeletal muscle disease. One hundred and ninety patients without proven heart or primary muscle disease [normal electrocardiogram (EKG), chest $X$ ray, serum creatine phosphokinase serum level (CPK)], without serologic evidence of $T$. cruzi infection, from an endemic area, were used to test the distribution of sporadic IgG anti-SRA in a population of hospitalized adults (Edgard dos Santos Hospital, Salvador, Bahia, Brazil).

Subjects with false-positive T. cruzi serology. Nine patients from non-endemic areas and negative travel history with clinically active secondary syphilis [(positive VDRL and fluorescent treponema antibody (FTA tests)] and false-positive serology for $T$. cruzi infection were selected from the New York Hospital clinics.

Subjects with infectious disease and negative T. cruzi serology. These were: 9 patients with secondary syphilis (positive VDRL and FTA tests); 12 convalescing children with rising antibody complement fixation titers against group B (1-6) Coxsackie virus antigens; 18 patients with congenital heart disease who developed the postpericardiotomy syndrome and positive complement fixation titers of antigroup B (1-6) Coxsackie virus; 12 patients with biopsy- and culture-proven Leishmania brasiliensis (mucocutaneous leishmaniasis); 12 patients with biopsy-and culture-proven L. mexicana mexicana (cutaneous leishmaniasis); 14 patients with culture-proven chronic pulmonary tuberculosis; 9 patients with biopsy-proven leprosy; 11 patients with scarlet fever and culture-proven group A $\beta$-hemolytic Streptococcus infection; 20 patients with serologic and/or biopsy evidence of Toxoplasma gondii infection without clinical myositis (normal serum CPK), including two infants with encephalopathy.

Subjects with heart disease other than primary myocardial disease. These were: 11 children with preceding group A $\beta$-hemolytic Streptococcus infection who fulfilled Jones's criteria of rheumatic fever and carditis (41); 7 subjects with valvular disease of rheumatic origin documented at autopsy; 21 patients with ischemic coronary artery disease with acute myocardial infarction (MI) of less than 10 days' duration, evolving EKG changes and elevated serum creatinine phosphokinase levels with myocardial bands (MB bands) ( 9 of these patients had had previous MIs); 22 patients with ischemic cardiomyopathy as documented by angiographic evidence of severe coronary artery disease and/or documentation of one or more previous MIs; 79 patients with documented diastolic/systolic hypertension and left ventricular hypertrophy.

T. cruzi-infected subjects with or without advanced cardiomyopathy. These 
were: 12 hospitalized children who showed freely swimming $T$. cruzi trypomastigotes in wet mounts of peripheral blood; 46 patients with positive $T$. cruzi serology who were asymptomatic and in apparent good health (negative chest $X$ ray, EKG, CPK); 74 patients with positive $T$. cruzi serology and symptomatic advanced cardiomyopathy. Objective evidence of their disease was dyspnea-limited exercise intolerance, and in most patients this was documented by invasive hemodynamic study which indicated reduction of cardiac index and elevation of pulmonary wedge pressure, cardiomegaly, marked bradycardia, and varying degrees of heart block or right bundle branch block and/or left anterior hemiblock and/or intraventricular conduction defects.

Subjects with advanced primary cardiac and skeletal muscle disease. These were: 14 patients with idiopathic congestive cardiomyopathy with no evidence of ischemic heart disease; 6 boys with biopsy-proven Duchenne muscular dystrophy and markedly elevated serum CPK levels; 7 patients with biopsy-proven polymyositis and elevated serum CPK levels. Sera from eight mothers or female relatives of boys with Duchenne muscular dystrophy with negative skeletal muscle biopsy and unremarkable serum CPK levels were also studied.

\section{Data Reduction and Analysis}

Two by two tables were constructed from the data and statistical analysis was done with the Fisher exact tests $(42,43)$. Significance was assigned to values $P$ $<0.05$.

\section{RESULTS}

\section{Serologic Specificity and Cross-reaction of Antisarcoplasmic Reticulum Membrane Antibody (aSRA)}

Normals. The mean and standard deviation of the mean of IgG aSRA activity of the normal volunteers was 1:80 \pm 1.6 twofold dilutions (Table 1). The highest normal titer was $1: 320 ; 91 \%$ of the readings were $\leqslant 1: 160(N=70)$.

Titers of the study groups were considered positive when they were greater than two standard deviations from the mean of normal control sera. Thus, aSRA titers $\geqslant 1: 640$ were positive; titers of 1:320 were borderline; titers $\leqslant 1: 160$ were negative.

Sporadic distribution of anti-SRA. The distribution of aSRA was studied in a selected group of 190 patients admitted to the Edgar dos Santos Hospital, Salvador, Bahia, Brazil, with the exclusion of patients who were serologically positive for syphilis or for T. cruzi infection and who had heart, primary myocardial, or skeletal muscle or connective tissue diseases. One hundred and seventy-two patients $(90.5 \%)$ had negative titers and five had positive titers $(2.6 \%)$ (Table 1$)$. Interestingly, four of the five positive patients had admission diagnoses which are known to occasionally show antibodies to target organs (hyperthyroidism, chronic hepatitis, diabetes mellitus, and cholangitis); however, the prevalence of positive titers was not statistically significantly different from the distribution shown among 70 normal volunteers (Table 1).

Concordance between antisarcolemma (aSLA) and antisarcoplasmic reticulum 
TABLE 1

NORMAL and SPORADIC IgG aSRA Titers

\begin{tabular}{|c|c|c|c|c|c|}
\hline Normal & $\begin{array}{c}\text { Negative } \\
\leqslant 1: 160\end{array}$ & \multicolumn{2}{|l|}{$\begin{array}{c}\text { Borderline } \\
1: 320\end{array}$} & \multicolumn{2}{|l|}{$\begin{array}{l}\text { Positive } \\
\geqslant 1: 640\end{array}$} \\
\hline$N=70$ & $64(91.4 \%)$ & \multicolumn{2}{|l|}{$6(8.6 \%)$} & \multicolumn{2}{|l|}{$0(0.0 \%)$} \\
\hline \multicolumn{6}{|c|}{ Sporadic IgG aSRA in 190 hospitalized subjects without primary muscle disease } \\
\hline \multicolumn{2}{|c|}{$\begin{array}{l}\text { Negative } \\
\leqslant 1: 160\end{array}$} & \multicolumn{2}{|l|}{$\begin{array}{c}\text { Borderline } \\
1: 320\end{array}$} & \multicolumn{2}{|l|}{$\begin{array}{l}\text { Positive } \\
\geqslant 1: 640\end{array}$} \\
\hline \multirow{12}{*}{\multicolumn{2}{|c|}{$172(90.5 \%)$}} & Diabetes mellitus & 2 & Hyperthyroidism & 1 \\
\hline & & Fibrocystic disease & 1 & Blastomycosis & 1 \\
\hline & & Glioma & 1 & Diabetes mellitus & \\
\hline & & Esophageal stricture & 1 & Chronic hepatitis & \\
\hline & & Herpes zoster & 1 & Cholangitis & 1 \\
\hline & & Schistosomiasis & 2 & $5(2.6 \%) \mathrm{NS}$ & \\
\hline & & Aplastic anemia & 1 & & \\
\hline & & Osteomyelitis & 1 & & \\
\hline & & Malaria & 1 & & \\
\hline & & Sepsis & 1 & & \\
\hline & & Cholecystitis & 1 & & \\
\hline & & $13(6.8 \%) \mathrm{NS}$ & & & \\
\hline
\end{tabular}

membrane titers. Thirty-eight sera (16 negative, 6 borderline, and 16 positive aSRA) were selected to study the degree of concordance with IgG aSLA titers. SLA preparations from a human heart and from rabbit hearts yielded exactly the same results (data not shown). Actomyosin-extracted human heart microsomes also gave the same results. As can be seen in Table 2, there was concordance of titers in 36 of 38 sera ( $94.7 \%$ ). The high agreement was supported by study of inhibition of IgG aSRA in 16 positive sera using rabbit SLA preparations (Table 2). Of 16 positive aSRA sera, 12 were inhibited by $0.45 \pm 0.02 \mu \mathrm{g} / \mathrm{ml}$ SLA (75\%) while the remaining 4 positive aSRA required 2.5 to $10 \mu \mathrm{g} / \mathrm{ml} \mathrm{SLA}$ to effect complete inhibition (Table 2).

TABLE 2

CONCORdANCE OF ASRA AND ASLA IgG TITERS

\begin{tabular}{|c|c|c|c|c|}
\hline & \multirow[b]{2}{*}{$\begin{array}{l}N \\
38\end{array}$} & \multicolumn{3}{|c|}{ IgG aSRA } \\
\hline & & $\begin{array}{c}\text { Negative } \\
\leqslant 1: 160\end{array}$ & $\begin{array}{c}\text { Borderline } \\
1: 320\end{array}$ & $\begin{array}{c}\text { Positive } \\
\geqslant 1: 640\end{array}$ \\
\hline \multirow{6}{*}{ IgG aSLA } & $\begin{array}{l}\text { Negative } \\
\leqslant 1: 160\end{array}$ & 16 & 1 & 1 \\
\hline & $\begin{array}{l}\text { Borderline } \\
1: 320\end{array}$ & 0 & 5 & 0 \\
\hline & $\begin{array}{l}\text { Positive } \\
\geqslant 1: 640\end{array}$ & 0 & 0 & 15 \\
\hline & \multicolumn{3}{|c|}{ IgG aSRA inhibition by SLA $(\mu \mathrm{g} / \mathrm{ml})$} & \\
\hline & $N$ & $2.5-10.0$ & $0.45 \pm 0.02$ & \\
\hline & 16 & $4(25 \%)$ & $12(75 \%)$ & \\
\hline
\end{tabular}


TABLE 3

CONFOUNDING IgG aSRA ACTIVITY

\begin{tabular}{|c|c|c|c|c|}
\hline & $N$ & $\begin{array}{c}\text { Negative } \\
\leqslant 1: 160\end{array}$ & $\begin{array}{c}\text { Borderline } \\
1: 320\end{array}$ & $\begin{array}{l}\text { Positive } \\
\geqslant 1: 640\end{array}$ \\
\hline \multicolumn{5}{|c|}{ A. Subjects with false-positive $T$, cruzi serology } \\
\hline Syphilis $^{a}$ & 9 & 1 & 0 & $8(88 \%)$ \\
\hline \multicolumn{5}{|c|}{ B. Subjects with negative $T$. cruzi serology } \\
\hline Syphilis $^{a}$ & 9 & 6 & 0 & $3(33 \%)$ \\
\hline Coxsackie B Virus & 12 & 5 & 3 & $4(33 \%)$ \\
\hline \multicolumn{5}{|l|}{$\begin{array}{l}\text { Post pericardiotomy } \\
\text { syndrome with } \\
\text { positive Coxsackie }\end{array}$} \\
\hline B serology & 18 & 14 & 0 & $4(22 \%)$ \\
\hline Leishmaniasis $^{b}$ & 24 & 21 & 1 & $2(8 \%) \mathrm{NS}$ \\
\hline Leprosy & 9 & 5 & 3 & $1(11 \%) \mathrm{NS}$ \\
\hline Tuberculosis & 14 & 13 & 1 & 0 \\
\hline Toxoplasmosis ${ }^{c}$ & 20 & 16 & 4 & 0 \\
\hline Scarlet fever & 11 & 11 & 0 & 0 \\
\hline
\end{tabular}

${ }^{a}$ All patients had clinical secondary syphilis and were from non-endemic areas and with a negative travel history. Absorption of sera with VDRL antigen abolished aSRA activity.

${ }^{b}$ Twelve subjects had cutaneous leishmaniasis, the rest the mucocutaneous form. All of these subjects came from areas endemic for both $T$. cruzi and Leishmania.

${ }^{c}$ None had clinical myositis with elevated serum CPK. Two newborns had severe encephalitis.

Confounding anti-SRA titers. SRA and SLA preparations were immunologically reactive with antibody in syphilitic sera due to the presence of the Wasserman antigen (cardiolipin) in the lipid contaminant (Table 3). aSRA reactivity of syphilitic sera was abolished by preincubation with VDRL antigen whereas no reduction of titers was seen in the sera of non-syphilitic patients (data not shown). Interestingly, 9 of 18 syphilis sera of patients with positive VDRL and positive fluorescent treponema antibody (FTA) tests yielded positive $T$. cruzi serology (Table 3). Of 12 sera from patients with serologic evidence of Coxsackie B virus infection, 4 showed abnormal aSRA (33\%) (Table 3). Four of a group of 18 sera from patients with the post-pericardiotomy syndrome who had positive $(\geqslant 1: 32)$ complement fixation titers for Coxsackie B virus also showed positive aSRA activity (22\%). The sera of patients with obligatory intracellular infection with the organisms of cutaneous or mucocutaneous leishmaniasis and toxoplasmosis did not give rise to a significant prevalence of aSRA (Table 3). None of the patients with established scarlet fever had abnormal titers of IgG aSRA.

Fortuitous association of anti-Coxsackie B and anti-SRA activities. The sera of 56 patients ( 27 negative, 9 borderline, 20 positive aSRA) were selected for the determination of anti-Coxsackie B (1-6) complement fixation titers (aCoxsackie B) in a blind study. Fourteen sera were selected randomly from the group of normal volunteers. The code was broken at the end of the study and the results tabulated (Table 4).

Table 4 shows that only 20 of 56 (35.7\%) sera yielded good agreement in titers, however, 36 of $56(64.3 \%)$ did not. When these data were compared to the results obtained with 14 randomly selected normal sera, no statistical differences were obtained (Table 4). The low degree of concordance between aSRA and aCoxsackie 
TABLE 4

Fortuitous AsSOCIATION OF ANTI-COXSACKIE B AND aSRA TITERS

\begin{tabular}{|c|c|c|c|c|c|}
\hline & & & \multicolumn{3}{|c|}{ IgG aSRA } \\
\hline & & & $\begin{array}{c}\text { Negative } \\
\leqslant 1: 160\end{array}$ & $\begin{array}{c}\text { Borderline } \\
1: 320\end{array}$ & $\begin{array}{c}\text { Positive } \\
\geqslant 1: 640\end{array}$ \\
\hline \multirow{5}{*}{$\begin{array}{l}\text { aCoxsackie B } \\
\text { (Types 1-6) }\end{array}$} & & $\begin{array}{l}\text { Negative } \\
\leqslant 1: 8\end{array}$ & 12 & 4 & 8 \\
\hline & & $\begin{array}{l}\text { Borderline } \\
1: 16\end{array}$ & 11 & 5 & 9 \\
\hline & & $\begin{array}{l}\text { Positive } \\
\geqslant 1: 32\end{array}$ & 4 & 0 & 3 \\
\hline & \multicolumn{4}{|c|}{ aCoxsackie B (1-6) by complement fixation } & \\
\hline & $N$ & $\begin{array}{c}\text { Negative } \\
\leqslant 1: 8\end{array}$ & $\begin{array}{c}\text { Borderline } \\
1: 16\end{array}$ & $\begin{array}{c}\text { Positive } \\
\geqslant 1: 32\end{array}$ & \\
\hline Normals & 14 & $5(35.7 \%)$ & $6(42.9 \%)$ & $3(21.4 \%)$ & \\
\hline
\end{tabular}

B titers (35.7\%) and the high prevalence of positive aCoxsackie B titers among normal subjects (21.4\%) indicate that significant fortuitous associations exist between the two and therefore no further conclusions can be made from the study reported here.

\section{Clinical Specificity of aSRA in Primary Muscle Disease}

Patients with serologic evidence of T. cruzi infection (Chagas' disease). The sera of 2 of $12(16.7 \%)$ patients with acute Chagas' disease with demonstrable $T$. cruzi parasitemia showed abnormally high IgG aSRA activity (Table 5) and this prevalence was not significant by the Fisher exact test. Of 46 asymptomatic patients without clinically evident cardiomyopathy, 9 showed elevated IgG aSRA activity (19.6\%), and this prevalence was statistically significant by the Fisher exact test when compared with the prevalence of aSRA obtained from normal subjects or from the group of hospitalized subjects without primary myocardial or skeletal muscle disease (Table 1). In sharp contrast, 35 of 74 symptomatic chronic Chagas' disease patients with cardiomyopathy showed elevated titers of IgG aSRA (47.3\%) (Table 5). This value is statistically significantly different from

TABLE 5

Prevalence of IgG aSRA in Patients with Seropositive $T$. cruzi Infection

\begin{tabular}{lcccc}
\hline & $N$ & $\begin{array}{c}\text { Negative } \\
\leqslant 1: 160\end{array}$ & $\begin{array}{c}\text { Borderline } \\
1: 320\end{array}$ & $\begin{array}{c}\text { Positive } \\
\geqslant 1: 640\end{array}$ \\
\hline Acute parasitemia & 12 & 8 & 2 & $2(16.7 \%)^{a}$ \\
Without cardiomyopathy & 46 & 30 & 7 & $9(19.6 \%)^{b}$ \\
With cardiomyopathy & 74 & 23 & 16 & $35(47.3 \%)^{c}$ \\
\hline
\end{tabular}

a NS vs patients from endemic area without primary muscle disease.

${ }^{b} P<0.001$ vs patients from endemic area without primary muscle disease.

${ }^{c} P<0.001$ vs seropositive $T$. cruzi patients without cardiomyopathy. 
TABLE 6

Prevalence of IgG aSRa in Patients with Advanced Primary Muscle Disease of the Heart and SKeletal Muscle

\begin{tabular}{lcccc}
\hline & $N$ & $\begin{array}{c}\text { Negative } \\
\leqslant 1: 160\end{array}$ & $\begin{array}{c}\text { Borderline } \\
1: 320\end{array}$ & $\begin{array}{c}\text { Positive } \\
\geqslant 1: 640\end{array}$ \\
\hline Idiopathic cardiomyopathy & 14 & 5 & 2 & $7(50.0 \%)$ \\
Duchenne muscular dystrophy & 6 & 2 & 0 & $4(66.7 \%(7)$ \\
Polymyositis & 7 & 2 & 0 & $5(71.4 \%)$ \\
\hline
\end{tabular}

Note. Versus normal, $P<0.001$.

the prevalences obtained from normal subjects (Table 1) and from asymptomatic subjects with serologic evidence of $T$. cruzi infection (Table 5) $(P<0.001)$.

Patients with primary myocardial and skeletal muscle diseases. Of 14 patients with intractable congestive heart failure due to idiopathic cardiomyopathy, 7 showed abnormal aSRA titers (50.0\%) (Table 6). The sera of 4 of 6 boys with Duchenne muscular dystrophy and markedly elevated serum CPK levels showed abnormal aSRA titers $(66.7 \%)$. Five of seven subjects with clinically active polymyositis and elevated serum CPK levels had elevated aSRA titers (71.4\%) (Table 6). Each group showed a statistically significant difference when compared with the distribution obtained from normal subjects or from the distribution obtained from sporadic hospitalized patients (Table 1). Patients with rheumatic fever and/ or carditis, acute myocardial infarction, ischemic cardiomyopathy, and hypertension showed a normal distribution of aSRA (Table 7).

One patient of a group of 22 with ischemic cardiomyopathy $(4.5 \%)$ and 4 patients of a group of 79 with hypertensive cardiovascular disease $(5.1 \%)$ had abnormal aSRA serum titers (Table 7). These values are not statistically different from those obtained from the survey for sporadic cases or from the normal control group (Table 1).

Identification of a T. cruzi 25-kDa Antigen (P25) of Clinical Specificity for Chagas' Cardiomyopathy

Epimastigote-specific antibodies in sera from patients with Chagas' disease. Solubilized $\left[{ }^{35} S\right]$ methionine-labeled epimastigote antigens were incubated with sera from chagasic patients. Precipitated polypeptides were identified by electrophoresis in SDS-containing gels and flurography. They served to define the spec-

TABLE 7

Prevalence of IgG aSRa in Patients with Secondary Heart Diseasf

\begin{tabular}{lcccc}
\hline & $N$ & $\begin{array}{c}\text { Negative } \\
\leqslant 1: 160\end{array}$ & $\begin{array}{c}\text { Borderline } \\
1: 320\end{array}$ & $\begin{array}{c}\text { Positive } \\
\geqslant 1: 640\end{array}$ \\
\hline $\begin{array}{l}\text { Rheumatic fever/carditis } \\
\text { Acute myocardial infarction }\end{array}$ & 11 & 11 & 0 & 0 \\
$\begin{array}{l}\text { Ischemic cardiomyopathy } \\
\text { Hypertension with left }\end{array}$ & 21 & 20 & 1 & 0 \\
$\quad$ ventricular hypertrophy & 79 & 71 & 2 & $1(4.5 \%) \mathrm{NS}$ \\
\hline
\end{tabular}



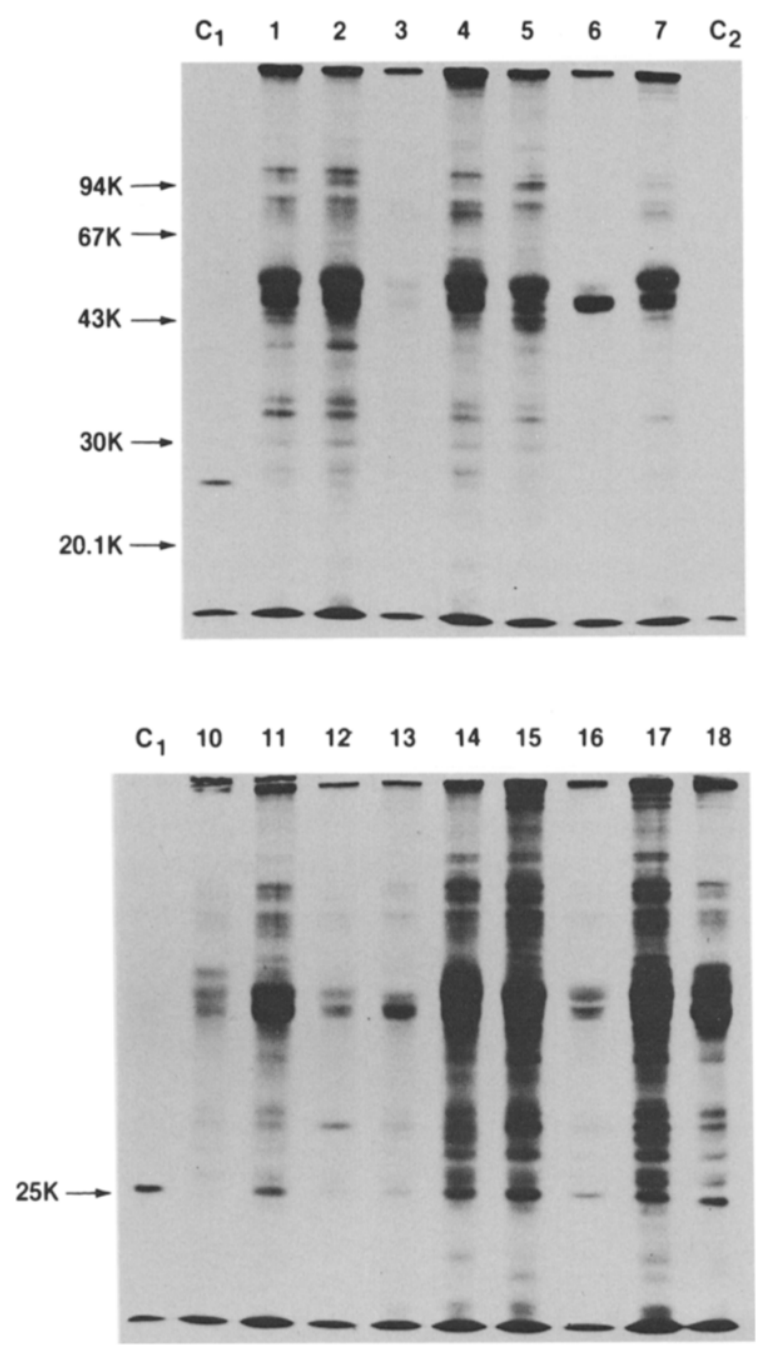

Fig. 1. Fluorograms of polypeptides precipitated from $\left.{ }^{35} \mathrm{~S}\right]$ methionine-labeled extracts of $T$. cruzi epimastigotes by serum samples from Chagasic patients without (1-7) and with (10-18) cardiomyopathy. $C_{1}$, serum from patient with non-ischemic idiopathic cardiomyopathy: $C_{2}$, normal control serum.

ificity of the antibody species present in the various serum samples. Two sets of serum samples were used in these studies. They were obtained from patients with chronic $T$. cruzi infection; one set (17 samples) was from patients with advanced cardiomyopathy, the other set (12 samples) from patients without cardiomyopathy. Figure 1 shows representative immunoprecipitation patterns; tracks 1 through 7 represent serum samples from chagasic patients without cardiomyopathy, and tracks 10 through 18 from patients with cardiomyopathy. Two control sera were included: $C_{1}$ was from a patient with non-ischemic idiopathic cardiomyopathy, and $\mathrm{C}_{2}$ from a normal individual. As will be discussed below, serum 
$\mathrm{C}_{1}$ reacted specifically with an epimastigote antigen with a molecular weight of 25,000 . The background precipitation with control serum $\mathrm{C}_{2}$ was negligible.

The two sets were similar in that some of the sera reacted with only a few epimastigote antigens (Nos. 3,6,10,13, and 16); whereas others reacted with a large number of polypeptides ranging in molecular weight from less than 20.000 to more than 100,000 . A significant difference between both sets was the ability to react with the polypeptide with molecular weight of 25.000 (P25). Except for serum No. 10, all sera shown in Fig. 1 from $T$. cruzi-infected patients with cardiomyopathy contained antibodies against P25, whereas none of the sera from $T$. cruzi-infected patients without cardiomyopathy reacted with P25. The reaction was strongest in samples $14,15,17$, and 18, which also contained the most parasite-specific antibodies. Samples 11 and 16 with a relatively restricted antibody response also reacted strongly with $\mathrm{P} 25$, whereas samples 12 and 13 with only a few epimastigote-specific antibodies reacted weakly with P25. Sixteen out of a total of 17 serum samples from $T$. cruzi-infected patients with cardiomyopathy reacted with $\mathrm{P} 25$. whereas none of 12 serum samples from Chagas' patients without cardiomyopathy reacted with this polypeptide.

$P 25$ in amastigotes. $T$. cruzi epimastigotes, the insect form, replicate axenically and metabolic labeling is accomplished rather easily. Trypomastigotes, the bloodstream form, do not replicate and metabolic labeling is inefficient; attempts to precipitate $\mathrm{P} 25$ from an extract of $\left[{ }^{35} \mathrm{~S}\right]$ methionine-labeled trypomastigotes gave variable and inconclusive results (data not shown). Amastigotes, the intracellular form, were labeled in vivo by incubating infected non-replicating myoblast cells in the presence of $\left[{ }^{35} \mathrm{~S}\right]$ methionine. As a control, uninfected non-replicating myoblast cells were radiolabeled. Extracts from each cell type were incubated with the $\mathrm{P} 25$ positive reference serum sample $\left(\mathrm{C}_{1}\right)$ from the patient with idiopathic cardiomyopathy. This serum reacted with a polypeptide with a 25,000 molecular weight that was present in extracts from infected cells but not uninfected cells (Fig. 2). Control sera did not react with this amastigote polypeptide. Thus the reactive 25,000 -Da polypeptide is present in $T$. cruzi amastigotes and epimastigotes.

The presence of P25 does not appear restricted to the $T$. cruzi Merc 2 D14 strain because similar results were obtained with extracts from $\left[{ }^{35} \mathrm{~S}\right]$ methioninelabeled epimastigotes of the Colombia strain (data not shown).

P25-specific antibodies in sera from patients with primary muscle diseases. The strongest reaction was observed with serum from a patient with non-ischemic idiopathic cardiomyopathy, and the immunoprecipitate using this serum was included as a positive reference control in each gel $\left(C_{1}\right.$ in Fig. 2). After fluorography, the gels were scanned and the surface areas representing P25 were calculated. Those sera which precipitated P25 to more than 20\% of the positive reference serum $C_{1}$ were considered to contain antibodies against P25. Most of the serum samples reacted with a small number of $T$. cruzi antigens as a result of nonspecific binding. However, some of the serum samples reacted specifically with P25 indicating that these sera also contained antibodies against this antigen.

Coelectrophoresis established that each of the $\mathrm{P} 25$ polypeptide species precip- 


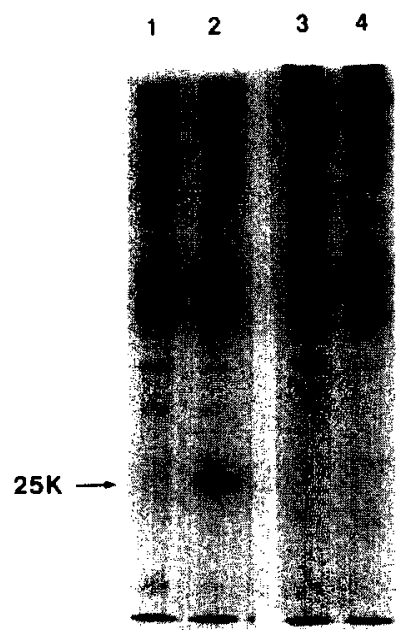

Fig. 2. Fluorograms of polypeptides precipitated by control and P25-positive serum ( $C_{1}$ in Fig. 1) from $\left[{ }^{35} \mathrm{~S}\right.$ ] methionine-labeled irradiated myoblast cells infected with $T$. cruzi (a source of amastigotes) or uninfected irradiated myoblast cells. 1 , infected cells plus control serum; 2 , infected cells plus P25positive serum; 3, uninfected cells plus control serum: 4, uninfected cells plus P25-positive serum.

itated by the positive sera migrated with identical mobility, suggesting that each P25 positive serum sample recognized the same antigen.

Representative results are shown in Fig. 3. All 18 sera from individuals without any clinical evidence of disease failed to react with $T$. cruzi antigens (examples are tracks No. 17 and $\mathrm{C}_{2}$ ). Tracks 1 through 5 show representative serum samples from boys with Duchenne's muscular dystrophy of which samples 3 and 4 precipitated P25. Tracks 6 through 10 contain the material precipitated by sera from mothers and female relatives of patients with Duchenne's muscular dystrophy who themselves did not exhibit any clinical symptoms, and three of these reacted with P25 (tracks 7, 9, and 10). Track 11 contains a non-reactive serum sample from a patient with idiopathic progressive congestive cardiomyopathy. Tracks 12 , 13 , and 14 contain material precipitated by sera from patients with polymyositis, and tracks 12 and 14 were positive for P25. Tracks 15, 18, 19, and 20 show serum samples from patients with atherosclerotic coronary artery disease and myocardial infarction of which samples 15,18 , and 20 reacted with $\mathbf{P 2 5}$ (samples 18 and 20 reacted weakly but so did the positive control serum sample in this particular experiment). Sera from patients with ischemic cardiomyopathy due to atherosclerotic coronary artery disease or with scarlet fever and its sequelae (rheumatic fever, carditis, or chronic rheumatic heart disease) did not contain antibodies against P25. Sera from patients with a number of infectious diseases (toxoplasmosis, tuberculosis, leprosy, syphilis, and cutaneous leishmaniasis) were also negative. However, one out of two sera from cases with mucocutaneous leishmaniasis was positive (track 16). The latter two serum samples were obtained from an area endemic for Chagas' disease and reactivity with P25 could reflect an occult infection with $T$. cruzi, or it could reflect limited serological crossreactivity between $T$. cruzi and Leishmania (44). 

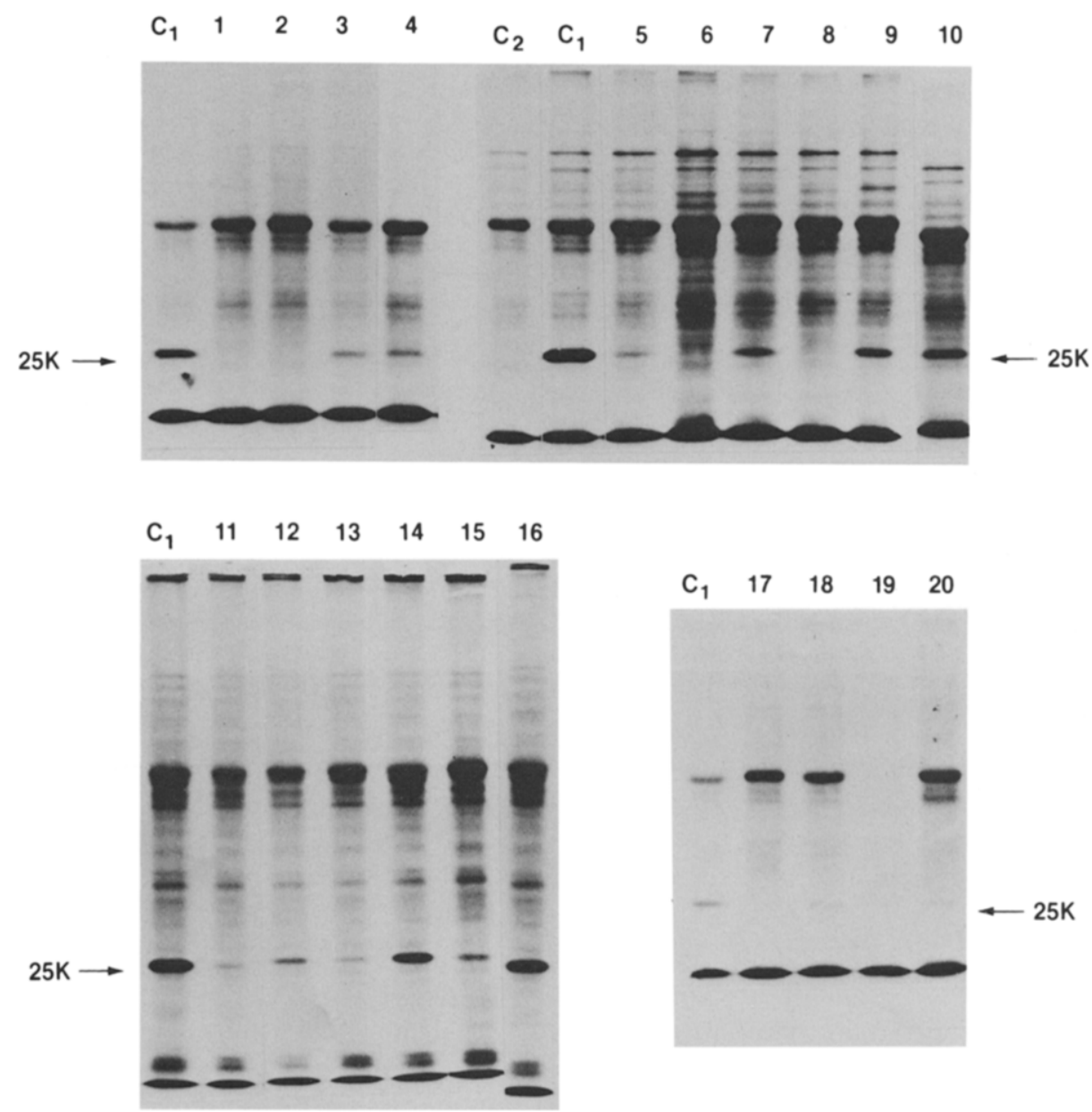

FIG. 3. Fluorograms of polypeptides precipitated from $\left[{ }^{35} S\right]$ methionine-labeled extracts of $T$. cruzi epimastigotes by serum samples from normal individuals and patients with primary muscle diseases. $C_{1}$ and 11 , patients with non-ischemic idiopathic cardiomyopathy; $C_{2}$ and 17 , normal controls; 1-5 boys with Duchenne's muscular dystrophy; $6-10$, asymptomatic mothers and sisters of boys with Duchenne's muscular dystrophy; 12-14, patients with polymyositis; 15 and 18-20, patients with atherosclerotic cardiovascular disease; 16. patient with mucocutaneous leishmaniasis.

\section{DISCUSSION}

Different types of antibody activity against sarcolemma antigens have been characterized in the sera of patients with chronic Chagas' disease. Recent data strongly indicate that these antibodies are not cross-reactive, since they are uniquely adsorbed by different antigen preparations. Antiheterophile (EVI) antibody is adsorbed with guinea pig red blood cells (rbc) (30), whereas anti- $\beta$ adrenoreceptor activity is abolished by $\beta$-adrenoreceptor-rich turkey rbc adsorption (29). Chagas' sera anti-laminin activity is adsorbed neither by guinea pig rbc nor by turkey rbc (Cossio, personal communication). The sarcolemma antigen preparation (SLA) used in this report is rich in $\beta$-adrenoreceptors (35) and the calcium translocating ATPase $(36,45)$ and thus anti-SLA titers are not specific 
for these two antigens. Results of the experiments reported here show a high degree of IgG cross-reactivity between heart sarcolemma preparations (human, rabbit) and rabbit skeletal muscle sarcoplasmic reticulum preparations enriched with the calcium-sequestering ATPase $(94.7 \%$ concordance, $N=38)$. These data strongly confirm previous observations on the cross-reactivity of aSRA with the myocardial sarcolemma (46).

In this report we determined the degree of clinical specificity of aSRA/aSLA antibody activity by conducting a prevalence study in groups of patients with established primary myocardial and skeletal muscle diseases. The results of this investigation show a strong association between elevated serum IgG antisarcolemma titers and advanced primary myocardial and skeletal muscle disease (Chagas' cardiomyopathy, idiopathic cardiomyopathy, polymyositis, and Duchenne muscular dystrophy). The prevalence of elevated IgG antisarcolemma activity in these four groups of patients ranged from 47.3 to $71.4 \%$ (mean $58.9 \pm$ $10.4 \%$ ). The clinical specificity of the IgG antisarcolemma reaction was confounded by patients with VDRL-FTA positive syphilis because of cardiolipin contamination of the lipid-rich sarcolemma antigens used in the serologic tests. Although no significant concordance was found between complement fixing antibodies to types 1 to 6 Coxsackie B antigens and IgG antisarcolemma titers, patients with the clinical diagnosis of Coxsackie B viral disease also gave confounding results (mean $27.5 \pm 5.5 \%$ ). Nevertheless, with the exception of syphilis and Coxsackie B virus disease, elevated IgG antisarcolemma levels are fairly indicative of an immune abnormality associated with primary cardiac and skeletal muscle diseases.

Elevated serum IgG antisarcolemma titers are not likely to be related to possible immune sequelae that may follow necrosis of myocardium or skeletal musclc. Clinical specificity was found when normal IgG antisarcolemma levels were measured in large numbers of other types of heart disease (mean $2.4 \pm$ 2.2\%: rheumatic carditis, ischemic cardiomyopathy, hypertension, acute myocardial infarction) and among infections of other etiology (mean $3.8 \pm 4.7 \%$ : scarlet fever, toxoplasmosis without clinical myositis, leprosy, tuberculosis, leishmaniasis). Moreover, abnormal IgG antisarcolemma titers could not be attributed to spurious phenomena because they were rarely encountered when titers were measured in a large group of hospitalized patients from an area endemic for Chagas' disease (Bahia, Brazil) who had no serologic evidence of $T$. cruzi infection or clinical evidence of primary muscle disease $(2.6 \%, N=190$ : Table 1$)$.

Among the groups of patients with primary muscle cell disease, those with $T$. cruzi infection provided the opportunity to compare the prevalence of IgG antisarcolemma activity in the earlier, preconditioned stages which precede the development of cardiomyopathy later. [For review of clinical stages of Chagas' disease, see Ref (13)]. The results of this comparison show that a few hospitalized patients with recent $T$. cruzi infection and parasitemia developed abnormal IgG antisarcolemma titers $(16.7 \%, N=12)$. Seropositive, asymptomatic patients with chronic $T$. cruzi infection also developed a low prevalence of elevated IgG antisarcolemma titers $(19.6 \%, N=46)$. These two groups of $T$. cruzi-infected patients contrasted sharply with the prevalence measured from hospitalized, seropositive 
patients with advanced cardiomyopathy $(47.3 \%, N=74)$. The abrupt high prevalence of IgG antisarcolemma activity among patients with advanced Chagas' cardiomyopathy suggests that the immune abnormality is closely associated with the pathogenesis of the myocardial cell damage.

The results of this study show a significant prevalence of abnormal IgG antisarcolemma titers in female relatives and boys with Duchenne muscular dystrophy, which is not known to have a relationship to an infectious agent. This observation should be viewed with caution, since no prospective study of possible opportunistic myotropic infections has been published with Duchenne muscular dystrophy, and further causative associations based on the results reported here should not be considered. There are notable studies which show the concurrence of Toxoplasma gondii infestation and polymyositis (47). A high prevalence of elevated anti-Coxsackie virus titers have been reported associated with polymyositis (48), the postpericardiotomy syndrome (49), and non-ischemic cardiomyopathy (50). Recent studies of autoantibody of patients with polymyositis suggest that the activity may be specifically directed against intracellular muscle histidyl-tRNA synthetase (51) and antibodies directed against tRNA and tRNAassociated proteins appear to be closely associated with polymyositis $(52,53)$. A hypothesis for the development of anti-tRNA antibody presupposes the induction of pathoimmunity by the binding of host histidyl tRNA synthetase to a viral RNA such as that carried by Coxsackie B virus (51). It has been shown that $T$. cruzi may acquire surface host antigens during parasitosis (54) but a similar mechanism to acquire autoantigenicity for Toxoplasma remains to be demonstrated.

The results of the experiments reported here demonstrate the presence of circulating antibody to a 25,000-Da polypeptide of $T$. cruzi in patients with advanced cardiomyopathy associated with chronic $T$. cruzi infection $(94.1 \% N=17)$. No such antibody was shown in 12 asymptomatic apparently healthy subjects seropositive to $T$. cruzi antigens. The $25-\mathrm{kDa} T$. cruzi polypeptide $\mathrm{P} 25$ probably has determinants that are cross-reactive with muscle antigens since anti-P25 activity was also defined by the sera of scveral paticnts with primary muscle discase without $T$. cruzi infection (1, idiopathic cardiomyopathy; 3 , polymyositis; 2 , Duchenne muscular dystrophy). Furthermore, all sera tested from mice and rabbits immunized with the sarcolemmal antigens used in this study also demonstrate anti-P25 activity (data not shown). A $25-\mathrm{kDa}$ surface glycoprotein of $T$. cruzi has been recently described (55). Anti-P25 was also recently shown in $T$. cruzi-infected inbred $\mathrm{C} 3 \mathrm{H}$ mice (38) which develop myocarditis and skeletal muscle myositis (56) that frequently results in death (57). These data suggest that the P25 antigen is intimately related to striated muscle fiber destruction and may implicate a discrete sarcolemmal component critical to the health of the myofiber. The data show that the presence of a circulating antibody to this characteristic $25-\mathrm{kDa} T$. cruzi antigen is fairly indicative of existing cardiomyopathy in chronic Chagas' disease.

\section{ACKNOWLEDGMENTS}

This investigation was supported by Research Grants HL-27493, Al 16282-02, and RR-05396 from the National Institutes of Health, United States Public Health Service. We thank Dr. M. M. de Bracco 
(Buenos Aires), Dr. C. G. Becker (The New York Hospital), Dr. P. Chiale (Buenos Aires), Dr. C. Cuba (Brasilia), Dr. C. Diez (Buenos Aires), Dr. T. Jones (The New York Hospital), Dr. M. Kaplan (North Shore University Hospital, New York), Dr. R. Klein (The New York Hospital), Dr. L. J. Kagen (Hospital of Special Surgery, New York), Dr. E. Segura (Buenos Aires), and Dr. J. M. Zabriskie (Rockefeller University) for their generous supply of antisera. We thank D. Schmatz (Merck Sharp \& Dohme Research Laboratories) for making available to us trypomastigotes and infected and uninfected myoblast cells. The technical assistance of A. Soyer and R. Bergman, and the statistical analysis of S. Lockhart, are gratefully acknowledged.

\section{REFERENCES}

1. Perloff, J. K., De Leon, A. C., Jr., and O'Doherty, D., Circulation 33, 625, 1966.

2. Heynisfield, S. B., McNish, T., Perkins, J. V., and Felner, J. M., Amer. Heart J. 95, 283, 1978.

3. Perloff, J. K., Henze, E., and Schelbert, H. R., Circulation 69, 33, 1984.

4. Denbow, C. E., Lie, J. T., Tancredi, R. G., and Bunch, T. W., Arthritis Rheum. 22, 1088, 1979.

5. Lynch, P. G., Brit. Heart J. 33, 416, 1971.

6. Cambridge, G., MacArthur, C. G. C., Waterson, A. P., Goodwin, J. F., and Oakley, C. M., Brit. Heart J. 41, 692, 1979.

7. Orimius, E., Acta Med. Scand. 183, 235, 1968.

8. Wilson, F. M., Miranda, Q. R., Chason, J. L., and Lerner, A. M., Amer. J. Pathol. 55, 253, 1969.

9. Laranja, F. S., Diaz, E., Nobrega, G., and Miranda, Q. R., Circulation 14, 1035, 1956.

10. Andrade, Z. A., Hospital (Rio de Janiero) 50, 803, 1956.

11. Andrade, Z. A., and Andrade, S. G., In 'Trypanosoma cruzi e Doenca de Chagas' (Z. Brener and Z. A. Andrade, Eds.), pp. 199-248, Guanabara Koogan, S. A., Rio de Janiero, 1979.

12. Suarez, J. A., Puigbo, J. J., Nava Rhode, J. R., Valero, J. A., and Yepez, C. G., In "Miocardiopatias" (H. Acquatella and P. A. Pulido, Eds.), pp. 5-17. Salvat Editores, S. A., Barcelona, 1982.

13. Santos-Buch, C. A., and Acosta, A. M., In "Immunology and Pathogenesis of Trypanosomiasis" (I. Tizard, Ed.), pp. 145-183, The Chemical Rubber Co., Cleveland, 1985.

14. Davies, M. J., In "The Pathology of the Heart" (A. Pomerance and M. J. Davies, Eds.), pp. 211250, Blackwell Scientific Publications, Oxford/London/Edinburgh/Melbourne, 1975.

15. Kakulas, B. A., Shute, G. H., and Leclerc, A. L. F., Proc. Aust. Assoc. Neurol. 8, 85, 1971.

16. Eckstein, R., and Hempel, W., Circulation 65, 1224, 1982.

17. Kaplan, M. H., and Frengley, J. D., Amer. J. Cardiol. 24, 459, 1969.

18. McCabe, J. C., Ebert, P. A., Engle, M. A., and Zabriskie, J. B., J. Surg. Res. 14, 158, 1973.

19. Das, S. K., Cullen, J. P., Dodson, V. N., and Cassidy, J. T., Circulation 44, 612, 1971.

20. Aretz, H. T., Chapman, C., Parillo, J. E., Palacios, I., and Fallon, J. T., Abs. Amer. J. Cardiol. 49, 985, 1982.

21. Currie, S., Saunders, M., Knowles, M., and Browne, A. E., Quart. J. Med. New Series XL, 63. 1971.

22. Dawkins, R. L., and Mastaglia, F. L., New Engl. J. Med. 288, 434, 1973.

23. Whitaker, J. M., and Engel, W. K., New Engl. J. Med. 286, 333, 1972.

24. Isenberg, D. A., Quart. J. Med., New Series LII, 297, 1983.

25. Laszlo, A., Hudak, J., Szabo, E., and Varga, L., Acta Paediatr. (Hungary) 24, 331, 1985.

26. Acosta, A. M., and Santos-Buch, C. A., Abs. Fed. Proc. 42, $2948,1983$.

27. Ellis, R. J.. Lillehei, C. W., Fischett, U. A., and Zabriskie, J. B., Circulation 42 (Suppl. II), 91. 1970.

28. Acosta, A. M., Sadigursky, M., and Santos-Buch, C. A., Proc. Soc. Exp. Biol. Med. 172, 364, 1983.

29. Borda, E., Pascual, J., Cossio, P. M., de la Vega, M., Arana, R., and Sterin-Borda, L., Clin. Exp. Immunol., 57, 679, 1984.

30. Cossio, P. M., Bustuoabad, O., Paterno, E., Jotti, R., Casanova, M. B., Podesta, M. R., Bolomo, N., Arana, R. M., and de Pascualini, C. D., Clin. Immunol. Immunopathol. 33, 165, 1984.

31. Huber, S. A., Lodge, P. A., Amer. J. Pathol. 116, 21, 1984. 
32. Grant, J., In "Handbook of Experimental Immunology" (D. M. Weir. Ed.). 3rd ed.. pp. 39.1039.11. Blackwell Scientific Publications. Oxford/London/Edinburgh/Melbourne, 1975.

33. Wahlin, B., and Perlmann, P., In "In Vitro Methods in Cell-Mediated and Tumor Immunity" (B. R. Bloom and J. R. David, Eds.), pp. 523 531, Academic Press. New York, 1976.

34. Lennette, E. H., and Schmidt, N. J.. "Diagnostic Procedures for Viral and Rickettsial Infections," American Public Health Association, Inc., New York, 1969.

35. Jones, L. R., Besch, H. R., Fleming, J. W., McConnaughey, M. M., and Watanahe, A. M...I. Biol. Chem. 254, 530. 1979.

36. MacLennan, D. H., J. Biol. Chem. 245, 4508, 1970.

37. Schmatz, D. M., and Murray, P. K., Parasitology 85, 115, 1982.

38. Zweerink, H. J.. Andersen. O. F. Greenblatt, H. C., and Murray, P. K., J. Parasitology 71, 43. 1985.

39. Guerreiro, C., and Machado, A., Bras. Med. 27, 225, 1913.

40. Cerisola, J. A., Alvarez, A., Lugones, H., and Rebolsan, J. B., Bol. Chil. Parasitol. 24, 54, 1969.

41. Report of American Heart Association Committee on Standards and Criteria for Programs of Care of the Council on Rheumatic Fever, Mod. Concepts Cardiovasc. Dis. 24, 291, 1955.

42. Croxton, E. F. "Elementary Statistics with Applications in Medicine and the Biological Sciences," Dover Publications, lnc., New York, 1959.

43. Daniel, W. W., "Biostatistics: A Foundation for Analysis in the Health Sciences," John Wiley \& Sons, New York/Chichester/Brisbane/Toronto/Singapore. 1983.

44. Pessoa, S. B., and Cardoso, F. A., Hospital (Rio de Janeiro) 21, 187, 1942.

45. Caroni, P., and Carafoli, E.. Nature (London) 283, 765, 1980.

46. Sadigursky, M., Acosta, A. M., and Santos-Buch. C. A., Amer. J. Trop. Med. Hyg. 31, 934, 1982.

47. Phillips, P. E., Kassan, S. S., and Kagen, L. J., Arthritis Rheum. 22, 209. 1979.

48. Christensen, M. L., Pachman, L. M., Maryjowski, M. C., and Friedman, J. M., Abs. Fed. Proc. 43, 93, 1984.

49. Engle, M. A., Zabriskie, J. B., and Senterfit, L. B.. "Heart-Reactive Antibody, Viral Illness and the Postpericardiotomy Syndrome. Correlates of a Triple-Blind, Prospective Study," Proc. Amer. Clin. Assoc., Waverly Press, Baltimore, 1976.

50. Goodwin, J. F., Circulation 50, 210, 1974.

51. Mathews, M. B., and Bernstein, R. M., Nature (London) 304, 177, 1983.

52. Rosa, M. D., Hendrick, J. P., Lerner, M. R., Steitz, J. A., and Reichlin, M., Nucleic Acids Res. 11, 853, 1983.

53. Hardin, J. A., Rahn, D. R., Shen. C., Lerner, M. R., Wolin, S. L., Rosa, M. D., and Steitz, J. A., J. Clin. Invest. 70, 141, 1982.

54. Chess, Q., Acosta. A. M., Sethi, J. K., and Santos-Buch, C. A., Infect. Immun. 38, 364, 1983.

55. Scharfstein, J., Rodrigues, M. M., Alves, C. A., de Souza, W., Previato, J. O., and MendosaPreviato, L., J. Immunol. 131, 972, 1983.

56. Federici, E. E., Abelman, W. H., and Neva, F. A., Amer. J. Trop. Med. Hyg. 13, 272, 1964.

57. Trischmann, T. M., J. Immunol. 130, 1953, 1983.

Received March 19, 1985; accepted with revision June 18, 1985 